\title{
El léxico carcelario mexicano durante el porfiriato y su lexicografía oculta: un estudio de caso
}

\author{
Ivo Buzek ${ }^{1}$ \\ Universidad Masaryk, República Checa
}

\begin{abstract}
Resumen
El artículo ofrece un estudio léxico-semántico del argot carcelario mexicano de la época del porfiriato tal como se aprecia en el "Vocabulario de la jerga carcelaria" que se recoge en la novela costumbrista La Chaquira (Belén por dentro) de Francisco García González, publicada por entregas en el periódico mexicano El Relámpago entre 1894 y 1895 . Se prestará atención a su estructura (léxico patrimonial español, nahuatlismos, anglicismos, etc.) y a los principales procesos lexicogenéticos que allí se documentan. Otro punto de interés será su relación y su estudio contrastivo con otros argots carcelarios hispanos, sobre todo el peninsular, desde una perspectiva tanto diacrónica como sincrónica de aquel entonces para poder documentar las direcciones de la evolución de este sociolecto como propiamente mexicano.
\end{abstract}

1 Para correspondencia, dirigirse a: Ivo Buzek (ibuzek@phil.muni.cz), Ústav románských jazyků a literatur, Masarykova univerzita, Filozofická fakulta, Arna Nováka 1, 60200 Brno, Česká republika. 
Palabras clave: argot carcelario, lexicología histórica, formación de palabras, cambio de significado, español mexicano.

MEXICAN PRISON SLANG DURING THE PORFIRIAN ERA AND ITS HIDDEN LEXICOGRAPHY: A CASE STUDY

\begin{abstract}
The aim of the paper is to offer a lexicological and semantic study of Mexican prison slang during the Porfirian era as it is appreciated in the "Prison Slang Vocabulary" that is included in the costume novel La Chaquira (Belén por dentro), by Francisco García González, published in instalments in a Mexican newspaper El Relámpago during 1894 and 1895. Attention will be paid to its structure (patrimonial vocabulary, Nahuatlisms, Anglicisms, etc.) and to principal word formation processes that can be found there. Another aim of study will comprehend its comparison with other Hispanic prison slangs, mainly the Spanish one, from the historical point of view. This historically focused comparison and analysis will show directions of evolution that would allow us to interpret this jargon as properly Mexican.
\end{abstract}

Keywords: prison slang, historical lexicology, word formation, semantic change, Mexican Spanish.

Recibido: 08/02/18 Aceptado: 30/04/18

\title{
1. INTRODUCCIÓN²
}

El léxico del español mexicano es un diasistema complejo en el que se plasman diversas influencias externas en combinación con tendencias internas propias de la lengua española como tal. Por una parte, es patente

2 Una primera versión de este trabajo fue presentada como ponencia en el VII Congreso Internacional de Léxico Español Actual (Università Ca'Foscari, Venezia, Campus Treviso, 27-28 de Noviembre de 2017) bajo el título "El léxico carcelario durante el porfiriato". Se inscribe dentro del proyecto Corpus diacrónico para el estudio de las actitudes lingüisticas en América y España en los siglos XVIII y XIX (FFI2016-76874-P), concedido por el Ministerio de Economía y Competitividad del Gobierno de España, y cuenta asimismo con el apoyo de la Facultad de Filosofía y Letras de la Universidad Masaryk. 
el fondo patrimonial del español moderno y la nivelación que se dio en el territorio dentro del marco de la koiné americana, refrescado continuamente con la llegada de nuevos colonos de diversas partes de España, así como con la migración interna y el contacto con las poblaciones indígenas, cuyas lenguas han ido enriqueciendo con préstamos el acervo léxico de la naciente variedad novohispana del español desde los comienzos de la época colonial hasta su consolidación como variante autónoma del español a finales del período virreinal (Company 2012), y es de suponer que siempre habrá tenido una rica variación geográfica y social (Martín Butragueño 2014).

En lo que se refiere a los estudios sobre la historia del léxico del español mexicano, se han publicado numerosos trabajos sobre los indigenismos léxicos y sobre el habla popular, por una parte (Lope Blanch 1965 y 1969; García Frazier 2006), así como sobre la constitución del vocabulario de registros elevados, propio del habla culta, y de los estilos formales de textos administrativos, jurídicos o científicos, por la otra (García Godoy 1998). No obstante, en la historiografía del lexicón del español mexicano hay una laguna patente que comprende la falta de estudios sistemáticos y metódicos del habla de las clases bajas urbanas desde el punto de vista histórico. Se han hecho estudios sobre el habla popular urbana y sobre los sociolectos de los marginales y marginados en el español mexicano actual (Lara 1992), pero en general faltan estudios sobre su historia y evolución (salvo Trejo 1961 o 1968).

Por supuesto, a continuación no vamos a presentar un estudio detallado sobre el tema, ya que este obviamente excedería los límites que puede tener el presente trabajo. Nuestras intenciones son mucho más modestas y esta vez nos limitaremos tan solo a comentar algunas características del argot carcelario mexicano de finales del siglo XIX, la época del porfiriato, tal como se aprecia en el "Vocabulario de la jerga carcelaria" que se recoge en la novela costumbrista La Chaquira (Belén por dentro) de Francisco García González, publicada por entregas en el periódico mexicano El Relámpago entre 1894 y 1895 . Al léxico argótico que aparece en el texto de la novela nos dedicaremos, por motivos de extensión, en otro estudio.

En primer lugar, examinaremos la filiación genética entre el argot carcelario (y el de la delincuencia) mexicano del porfiriato y la germanía española de los Siglos de Oro, puesto que, en principio, el argot de la delincuencia española áurea y el primitivo argot novohispano debían tener características en común y suponemos que algunos rasgos podían haberse conservado hasta la época del porfiriato. Asimismo, compararemos la muestra del argot mexicano con el argot de los malhechores españoles coetáneos para ver qué elementos seguían compartiendo y en qué ya diferían. 
La razón por la que hemos escogido el argot español es que para la base histórica solo tenemos los documentos de los delincuentes peninsulares.

A continuación, prestaremos atención a la estructura misma del argot mexicano y veremos qué presencia tiene allí el léxico patrimonial español en comparación con las influencias externas, comprendidas por nahuatlismos, anglicismos y otras posibles fuentes prestatarias. En lo que se refiere a su evolución interna, estudiaremos los procesos lexicogenéticos documentados, tanto los de la neología formal como los de la semántica.

En síntesis, nuestro fin es ofrecer en esta pequeña muestra del argot carcelario mexicano de finales del siglo XIX las tendencias que documentarían las posibles direcciones de la evolución de este sociolecto como propiamente mexicano o, si se quiere, "nacional".

\section{LA CHAQUIRA (BELÉN POR DENTRO) Y SU "VOCABULARIO DE LA JERGA CARCELARIA"}

Como ya hemos adelantado, nuestro estudio estará basado en una fuente literaria, la novela costumbrista La Chaquira (Belén por dentro), de Francisco García González, publicada por entregas en el periódico mexicano El Relámpago $^{3}$, entre 1894 y 1895 (en la portada se lee la fecha de publicación de 1894). Es una novela ambientada en general en los ámbitos populares mexicanos y la mayor parte del texto tiene la forma epistolar en la que los protagonistas, don Celso y Sofía, describen el ambiente de la cárcel de Belén, en la ciudad de México. La novela tiene un gran interés lexicológico, puesto que ofrece una buena muestra del argot carcelario de la época que aparece tanto directamente en los pasajes que describen la vida diaria en la cárcel, como en la forma de un "Vocabulario" que figura como apéndice de una de la cartas de don Celso a Cecilia, la madre de Sofía.

En el presente artículo nos vamos a centrar sola y exclusivamente en el léxico recogido en el "Vocabulario" y dejaremos las unidades léxicas argóticas que aparecen en el texto de la novela para otro estudio. Son varias las razones que, creemos, pueden justificar nuestra decisión. En

3 Accesible a través de la Hemeroteca Nacional Digital de México, disponible en http:// www.hndm.unam.mx/consulta/resultados/visualizar/558075be7d1e63c9fea1a400?resultado $=12 \&$ tipo $=$ publicacion\&intPagina $=0$ [Consulta: $28 / 1 / 2018]$. 
primer lugar, el "Vocabulario" es una sorpresa inesperada para el lector y es muy probable que hayan sido muy pocos los estudios de lexicología o lexicografía históricas del español que hayan sabido sobre su existencia. Por tanto, pertenecería al llamado "filón no entrevisto antes, el de la lexicografía oculta", como lo denominó en su momento Alvar Ezquerra (2004: 47). Otra razón sería que después de comparar los términos argóticos contenidos en los diálogos y sobre todo en las descripciones que ofrece la novela con los reunidos en el "Vocabulario", nos hemos dado cuenta de que coinciden mucho menos de lo que cabría esperar. En el texto de la novela hemos identificado 60 unidades léxicas que serían consideradas como argóticas, es decir, pertenecerían al argot carcelario y también, por extensión, al argot de la delincuencia del argot mexicano de la época (no sabemos si solo del área capitalina o si la extensión y el conocimiento eran más amplios); mientras que el "Vocabulario", como veremos a continuación, contenía 115 términos. Ahora bien, de las 60 unidades de la novela, solo 18 aparecen también en el "Vocabulario" y este hecho, en nuestra opinión, justificaría la decisión de poder estudiar ambos "sub-corpus" por separado. Parece como si al autor le hubiera dado pena de que casi un centenar de voces se habría quedado sin utilizar y por tanto (pero esto es una especulación nuestra) decidió incluirlas como apéndice de una de las misivas en forma de un breve listado de palabras manejadas en el ambiente de la prisión, potenciando así el valor costumbrista de la novela.

En lo que atañe al "Vocabulario" mismo, está caracterizado como vocabulario de "argot ó jerga" (188). No tiene, en principio, ningún título de encabezamiento, aunque no estamos del todo seguros, ya que la reproducción digital de la página 188, en concreto del párrafo en el que se habla sobre el vocabulario, es de muy mala calidad. El vocabulario ocupa las páginas 189-192 y es monodireccional: lenguaje general - argot (o "Nombre de los objetos" - "Jerga"). Como ya hemos adelantado, contiene 115 unidades léxicas jergales en total. A veces viene lematizado por formas no canónicas o presenta otras irregularidades (plurales de sustantivos, etc., como 'Pies. Alicates'; 'Calzones. Caballos'; 'Al robado. Esquelo'; o 'Castigo de barrer. Patinar') y en la última página (192) presenta tropiezos del orden alfabético. No incluye elementos de microestructura. Véanse a continuación dos muestras del "Vocabulario": el comienzo y el final. 


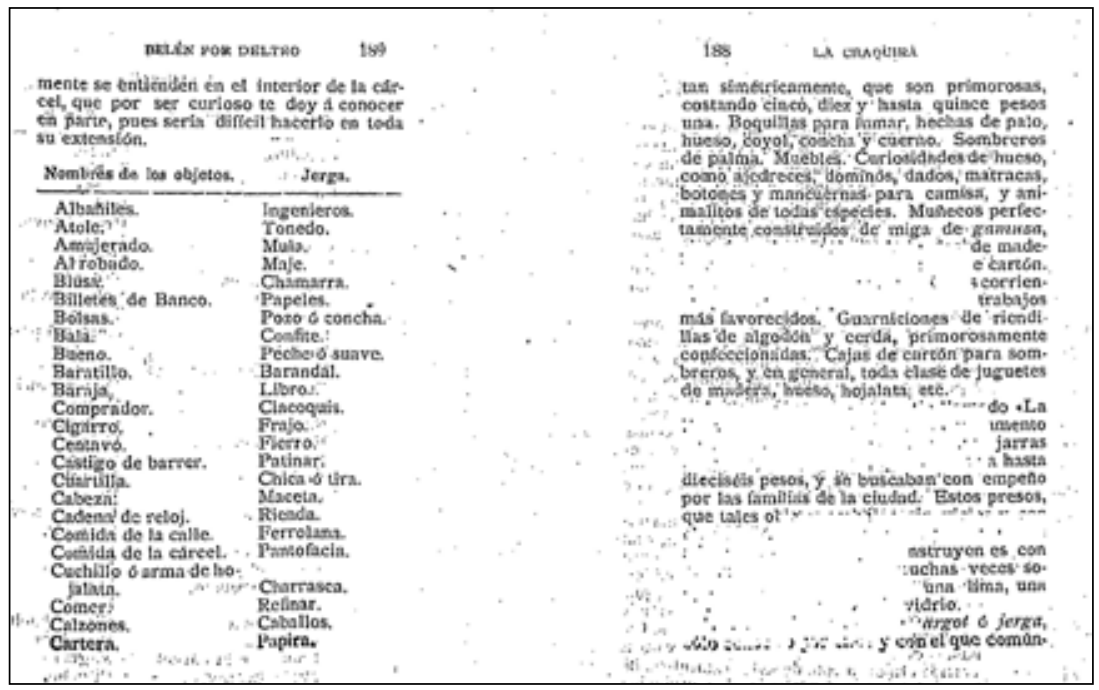

192

L. . chnquira

UะLix pok diatro

193

Nombro de los objotos: Jorgat.

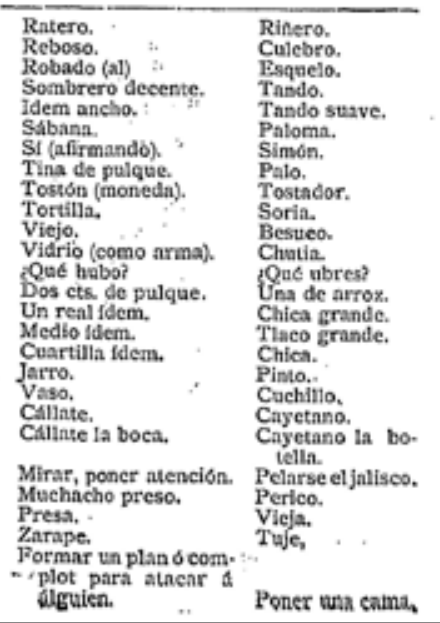

\section{xvl}

\section{SIGUEX IAS OBSEVACIOXTS \\ GENERALIS.}

Septiembre 27 de $189 \ldots$

Los porteros, que todos son presos, excepción de dos que son empleiulos), tie ben la obligacion de permanecer constant mente en st puesto, cerrando y abriend las puerias continuamente, $y$ aunque har muchus, son cinco las de mils responsabil dadi la reja del departamento de detenidos la de encausados, la de sentenciados $\delta$ pi tio de ẫos, la de bartolinas $y$ ta del de mu jeres.

In el departamento de pericos, el pres sirve a la ver de portero y golpe. Cadin por tero tiene a sa 1ado un goipe, que grita e nombre dol preso ó pide to quie se te orde na, ctayn orden repiten otros que se halla repartidos per toda la eíreel.

Hay, como los indicados, muchos presos en comision; pero con sus justus excepcio

Ahora bien, somos conscientes de que los textos literarios pueden fomentar estereotipos lingüísticos y que su autenticidad hay que tomarla con debida cautela, puesto que, como dice Oesterreicher, "lo específico del texto literario consiste exactamente en la posibilidad de fingir [...] todas las formas de este continuo concepcional" (2004: 734). Las palabras de Oesterreicher y de otros 
estudiosos que se han ocupado del valor de textos literarios para la historia de la lengua española (cf. Bustos Tovar 1995 y 1998) se refieren en general a la oralidad y a la interpretación adecuada de los pasajes dialogados. No obstante, en nuestro caso son casi siempre pasajes expositivos (en el estilo epistolario y el glosario como apéndice de una de las cartas). También es cierto que el valor documental de la novela no les pasó desapercibido a los historiadores (Garza 2007). Por tanto, creemos que podemos utilizar el "Vocabulario", y la novela en general, como una fuente legítima para la historia del argot carcelario mexicano de la época, siempre y cuando obremos con debida cautela.

\section{LA ESTRUCTURA DEL ARGOT CARCELARIO DEL "VOCABULARIO"}

A continuación vamos a pasar al estudio de las unidades léxicas argóticas que se recogen en el "Vocabulario". Como hemos dicho más arriba, en primer lugar estaremos interesados en su filiación genética con la germanía española áurea y en las características que guardan en común con el argot español coetáneo a la publicación de la novela; a continuación pasaremos al estudio de su estructura externa e interna.

Para poder interpretar adecuadamente el valor histórico de la unidades léxicas en cuestión, hemos acudido a varias obras de contraste. Para los aspectos contrastivos relacionados con el argot español, hemos acudido a varios de los repertorios léxicos de la germanía áurea (Chamorro 2002; Hernández Alonso y Sanz Alonso 2002); para el argot español de finales del siglo XIX hemos manejado el libro de Salillas 1896, que a su vez contiene dos vocabularios: "El vocabulario de germanía" (Salillas 1/1896) y el "Vocabulario del caló jergal" (Salillas 2/1896).

En lo que se refiere a su valor como léxico privativo de México, hemos acudido también a los diccionarios de mexicanismos publicados en la misma época (Ramos i Duarte 1895; García Icazbalceta 1899), a los diccionarios de mexicanismos y americanismos posteriores pero en general bien fundamentados (Santamaría 1942 y 2000 [1959]) y a los actuales, generales y de americanismos, cuya sincronía es relativa y se expande considerablemente al pasado $(D L E ; D A)$. Asimismo, hemos acudido a los diccionarios del argot de la delincuencia mexicana, aunque es cierto que son obras posteriores y entre el "Vocabulario" de la novela y los diccionarios del argot mexicano hay con frecuencia unos 40 o 50 años de diferencia. 


\subsection{LA FILIACIÓN HISTÓRICA CON EL ARGOT ESPAÑOL}

Si contrastamos las unidades léxicas argóticas mexicanas del "Vocabulario" con las nomenclaturas de inventarios de la germanía española áurea, aquí representados por Chamorro 2002, Hernández Alonso y Sanz Alonso 2002 y el "Vocabulario de germanía" recogido en Salillas 1896, notamos que es cierto que la germanía española estaba presente en los comienzos del argot mexicano, pero a su vez se hace sentir el peso de más de 300 años de evolución propia. La presencia de las voces de la germanía es más bien testimonial, pero es un testimonio que da fe de un pasado común. Son siete las voces que comparte el "Vocabulario" de La Chaquira con la germanía española áurea ${ }^{4}$ :

Blanca 'Plata' (Chamorro 2002: '2. Moneda blanca. Género de moneda de muy baja ley'; por generalización, de color pálido); Campanas 'Enaguas' (Chamorro 2002: 'Saya o basquiña'; Hernández Alonso y Sanz Alonso 2002: ídem.; Salillas 1896: 'Saya', en ambos vocabularios; por extensión, otro tipo de prenda); Libro 'Baraja' (Chamorro 2002: Libro de cuarenta y ocho 'Baraja de naipes'; Hernández Alonso y Sanz Alonso 2002: Libro de cuarenta y Libro real 'La baraja'); Lima 'Camisa' (Chamorro 2002: 'La camisa'; Hernández Alonso y Sanz Alonso 2002: ídem.; Salillas 1896: 'Camisa', en ambos vocabularios); Linternas 'Ojos' (Chamorro 2002: 'El ojo'; Hernández Alonso y Sanz Alonso 2002: ídem.); Paloma 'Sábana' (Chamorro 2002: 'Sábana'; Hernández Alonso y Sanz Alonso 2002: ídem.; Salillas 1/1896: ídem.); Poner una cama 'Formar un plan ó complot para atacar á alguien' (Chamorro 2002: 2. 'Tender trampa a un ladrón, preparar a la víctima de un robo'; probablemente generalizado en el español popular mexicano de la época, cf. Santamaría 1942 y 2000 [1959]: TENDERLE uno LA CAMA a otro. fig. fam. [...]-2. 'Ponerle una celada, prepararle un artificio para hacerle mal').

En lo que se refiere al léxico que los argots mexicano y español de finales del siglo XIX tenían en común, también aquí se trata o tan solo de un testimonio de un pasado común o de tendencias de evolución compartidas pero que no coincidían del todo. Al primer grupo pertenecían las voces germanescas campana, lima y paloma que ya hemos visto en el anterior párrafo y que aparecen también en el "Vocabulario del caló jergal" de Salillas (2/1896). Al segundo grupo pertenecían los gitanismos baiza 'mano' (en Salillas 2/1896 baste 'mano'), catirro(s) 'golpes' (en Salillas 2/1896 cate 'bofetada'), frajo

4 Mantenemos en todos casos la ortografía tal como aparece en el "Vocabulario". 
'cigarro' (en Salillas 2/1896 trajandil 'cigarro puro') y marro 'pan de la calle' (en Salillas 2/1896 manrró 'pan') que en ambos argots tenían variantes formales diferentes, pero las raíces comunes son innegables. En casos de culebro 'reboso' [sic] y papeles 'billetes de banco' puede que se trate de variantes formales de culebro 'faja' (Salillas 2/1896) y papil y papiro 'billete de banco' (ambos en Salillas 2/1896) y que tengan un pasado común, pero también es bien posible que se trate tan solo de parónimos con evolución independiente paralela.

\subsection{CONTINUIDAD CON EL ESPAÑOL EUROPEO}

El siguiente grupo de voces, que serían en realidad más bien tan solo unos casos sueltos, presenta continuidad con el español europeo o hasta se podría decir que pertenecerían al español general. Son acepciones que se documentan en diccionarios generales, aquí representados por el $D L E$, y en el caso de la palabra armar, también en el primer diccionario histórico del español (RAE 1933, en NTLLE).

Armar 'Molestar' (DLE: 8. tr. coloq. 'Provocar, causar una situación de confusión, ruido, alboroto'; pero sin acepciones convenientes en fuentes mexicanas); Timar 'Robar con engaño' (DLE: 1. tr. 'Quitar o hurtar con engaño'; Salillas 2/1896: 'Engañar por el procedimiento del timo. ॥ Estafar'; Chabat 1964: 'Engañar. Robar'); Trincar 'Robar' (DLE: 4. tr. 'robar (l tomar para sí o hurtar)'; Aguilar 1941: 'Reñir, timar'; Chabat 1964: 'Robar. Timar. Agarrar. Reñir. Coger’; Colín 1991: 'Perjudicar, causar daño, realizar el acto sexual').

\subsection{PALABRAS EN COMÚN CON EL ESPAÑOL POPULAR MEXICANO}

Son siete las palabras que el argot carcelario recogido en el "Vocabulario" compartía con el español popular mexicano de la época. Se trata tanto de voces patrimoniales que luego especializaron su significado en la variante mexicana del español (agüitar; chamarra; chica; cincho) como de nahuatlismos (chamaco y peche), y además figura aquí un gitanismo suelto (chagorra). Los préstamos de otras lenguas los trataremos más adelante por separado, pero según se puede leer en los comentarios incluidos en las fuentes de consulta utilizadas (en los casos de chagorra y peche, Santamaría 1942 y 2000 [1959] observa que son "desusadas hoy", mientras que en el de 
chamaco dice que es "usada comúnmente") fueron todas voces de uso común en el español popular mexicano y por ello los mencionamos también aquí.

En cuanto a los mexicanismos patrimoniales propios del ámbito de uso popular, pertenecen al léxico de la civilización de la zona: medida de pulque (chica), vestimenta popular (chamarra) y término de equitación (cincho). Se podría dudar de si se trata en estos casos de léxico argótico, pero como ha advertido Sanmartín (2006), los límites entre el argot de grupo, el argot común y el léxico popular son a veces borrosos.

Agüitar 'Dormir' (Ramos i Duarte 1895: 'Dormir' y Agüitarse 'Dormirse de la borrachera'; Santamaría 1942 y 2000 [1959]: 'En Méjico, entristecerse, abatirse, decaer el ánimo. Muy usado popularmente'; cf. Aguilar 1941: Agüitado 'Estar dormido, borracho'; Chabat 1964: Agüitado 'Dormido. Borracho. Apesadumbrado'; Colín 1991: Agüitarse 'Entristecerse, cohibirse, acobardarse' y Agüitado 'Entristecido, cohibido, turbado'; DA: Mx, ES. 'Turbarse, abatirse y desmoralizarse a causa de un contratiempo o desgracia. pop. (agüitiarse; ahuitar)' 2. tr. Mx, ES. 'Turbar, abatir o desmoralizar alguien o algo a una persona. pop. (ahuitar)'; DLE: agüitarse. El Salv. y Méx. 'entristecerse'); Chamarra 'Blusa' (Ramos i Duarte 1895: 'Cobertor. La chamarra es un vestido de jerga ó paño burdo. En Tampico llaman así á una chaqueta muy corta' y 'Zamarra, chaqueta'; García Icazbalceta 1899: 'Chaqueta negra de piel de cordero o de felpa rizada a imitación de aquella, y adornada, por lo común, de cordones, alamares y agujetas. Era traje favorito de guerrilleros y bandidos'; Santamaría 1942: 'En Méjico, chaqueta negra de piel de cordero propia de campesinos y jinetes.-2. En Guatemala y Venezuela, manta de lana burda, usada como cobija. Lo mismo en Méjico, entre los pelados.'; Santamaría 2000 [1959]: 'Chaqueta negra de piel de cordero o de felpa rizada a imitación de aquella, y adornada por lo común, de cordones, alamares y agujetas. Era traje favorito de guerrilleros y bandidos'; $D A$ : Mx, Pa, Ec, Bo; Ho, p. u. 'Cazadora, prenda de vestir'; DLE: 'Vestidura de jerga o paño burdo, parecida a la zamarra.'); Chica 'Cuartilla [de pulque]' (García Icazbalceta 1899: 'Medida para vender pulque'; Santamaría 2000 [1959]: 'Medida para vender pulque'; $D L E$ : 'Antigua medida de capacidad para el vino, igual a un tercio de cuartillo'; cf. DA: chico. Mx. 'Vaso pequeño de pulque, bebida tradicional mexicana'); Cincho 'Ceñidor' (Ramos i Duarte 1895: 'Ceñidor'; García Icazbalceta 1899: 'Cincha; la faja con que se asegura la silla sobre las bestias'; Santamaría 1942: 'Faja de distinto color en el pelaje de los animales, que abraza la región de la barriga trasversalmente'; Santamaría 2000 [1959]: 'Cincha; la faja con que se asegura la silla sobre las bestias' y 'Faja de distinto color en el pelaje de los animales, que abraza la región de la barriga trasversalmente'; $D A$ : Mx, Gu, Ho. 'Tira 
ancha de cuero que rodea el cuerpo del toro detrás de las patas delanteras y que sirve para sujetarse el que lo monta al toro en los jaripeos'; $D L E$ : Méx. 'cincha').

\subsection{Evolución EXTERna. CONTACTOS CON OtRAS LENGUAS}

No sorprende que encontremos en el "Vocabulario" indigenismos léxicos, pero al mismo tiempo hay que decir que los indigenismos forman un grupo muy reducido. Según hemos presentado en Buzek (2017), el argot mexicano de la delincuencia (igual que las demás hablas marginales) siempre ha sido urbano y, por tanto, los indigenismos léxicos que encontramos en él son los que ya se habían incorporado al acervo del español mexicano popular común, como hemos comentado en el anterior apartado.

Chamaco 'Muchacho' (Ramos i Duarte 1895: 'Muchacho'; Santamaría 1942 y 2000 [1959]: 'Voz genérica usada comúnmente y por extensión en Centro América y otras partes de América, por muchacho, niños pequeños o hasta antes de la pubertad.'); Clacoquis 'Comprador' (sin documentar en esta forma pero cf. Santamaría 1942: tlaco '2.m.pl. Dinero en general.-VAR.: claco'; DA: Mx. 'Dinero, moneda corriente. pop'; DLE: '2. m. Méx. dinero (\| moneda corriente'); Nagual 'Ladrón en la cárcel' (Santamaría 1942: '2. Brujo en general'; Franco 2014 [194?] 'Ladrón habitual'; cf. también nagualear: Santamaría 1942 'En Méjico, hurtar, robar. Muy vulgar', y Aguilar 1941 'Robar a los dormidos'); Peche ‘Bueno’ (Ramos i Duarte 1895: ‘Bueno’; Santamaría 1942 y 2000 [1959]: 'Bueno. Desusado hoy']); Tecolote 'Gendarmes' (Santamaría 1942 y 2000 [1959]: '2. fig. Apodo tradicional del gendarme, tal vez porque hace vida nocturna'; Franco 2014 [194?] 'Policía'; Chabat 1964: 'Gendarme. Policía'; Colín 1991: 'Policía preventivo'; DLE: 2. m. Méx. 'Miembro del cuerpo de Policía'; $D A$ : Mx. 'Policía vial mexicano, cuyo uniforme consta de camisa castaño claro y pantalones y gorra color café').

Hay dos palabras que probablemente serán anglicismos, aunque es cierto que pueden ser polémicas:

Laises 'Piojos' (¿del inglés louse - plural lice?; cf. Amor 2014 [1947]: Piojos (parásitos) 'Láicas, láises'; Aguilar 1941: Laico 'Piojo'; Chabat 1964: Laicas 'Piojos' y Laico 'Piojo'; Colín 1991: Laica 'Piojo'); Pinto 'Jarro' (sin documentación; tal vez del inglés pint 'medida de capacidad para líquidos', por metonimia 'jarra o jarro de cierta medida que contiene líquido'). 
Finalmente encontramos en el "Vocabulario" siete gitanismos. Puede que sean préstamos del argot español europeo y que posteriormente hayan sufrido adaptaciones y variación formal en el español mexicano. Algunos de ellos (frajo, catirro, marro y baiza) ya los hemos visto más arriba cuando hemos hablado sobre continuidades con el argot español:

Baiza 'mano' (Ramos i Duarte 1895: 'La mano'; Amor 2014 [1947]: Manos 'Váisas'; Aguilar 1941: baizas 'manos'; Chabat 1964: baisas 'manos'; Colín 1991: baisa(s) 'mano, manos'; DA: Mx, ES. 'Manos, miembro del cuerpo. delinc.'); Brisa 'Carne' (Ramos i Duarte 1895: 'Carne de res'; Santamaría 1942 y 2000 [1959]: 'En caló mejicano, carne de res, que a veces se dice también brinza.'; Aguilar 1941: Brizna 'Pieza de carne que se da en la prisión, ración'; Chabat 1964: Brizna 'Pedazo de carne. Ración de carne que se da en la cárcel'); Bruje 'Real' (Ramos i Duarte 1895: 'Real (moneda)'; sin más documentación mexicana; cf. en el caló español en Rebolledo 2006 [1909]: 'Real (monetario)'); Catirros 'Golpes' (Ramos i Duarte 1895: 'Golpe'; Santamaría 1942: 'En Sur América, golpe'; cf. también Santamaría 1942: CATE. m. Muy usado en Méjico, como en Andalucía, por golpe, bofetada, en lenguaje familiar); Chagorra 'Ídem [mujer] del pueblo' (Ramos i Duarte 1895: 'Mujer del pueblo'; Santamaría 2000 [1959]: 'Mujer del pueblo. Desusado hoy'; cf. también Santamaría 2000 [1959]: chaborra 'ramera, puta'; Aguilar 1941 y Chabat 1964: Chavorra 'Mujer'); Frajo 'Cigarro' (Amor 2014 [1947]: Cigarro de tabaco 'Frajo'; Aguilar 1941: 'Cigarrillo de tabaco’ y 'Cigarro'; Chabat 1964: 'Cigarrillo'; Colín 1991: 'Cigarrillo'; cf. Salillas 2/1896: Trajandil. (Caló prajandi) Caló cat. m. Cigarro puro); Marro 'Pan de la calle' (Amor 2014 [1947]: Pan 'Marro'; Aguilar 1941: 'Pan' y Manrro 'Comida'; Chabat 1964: 'Pan' y Manrro 'Comida. Pieza de pan en la prisión'; Colín 1991: 'Pan, bolillo’; cf. Salillas 2/1896: Manró. [etim.sanscr.] 'Pan').

\subsection{Evolución InTERna. Mecanismos lingüísticos}

En el siguiente apartado nos vamos a dedicar a voces que se han formado sobre bases claramente patrimoniales por evolución interna dentro del ámbito del argot mexicano según los patrones de la neología formal y la neología semántica habituales en el argot. Los autores que se han ocupado del tema (Alonso Hernández 1979 para la germanía áurea; Sanmartín 1998 y 2006 para el argot peninsular; y Martínez, Vila Rubio, Castañeda y Henao 2012 para el estudio contrastivo entre el argot español y el parlache colombiano) han llamado la atención sobre las modalidades del cambio 
semántico y los procesos formales, sin perder de vista la formación de las unidades fraseológicas, sobre todo de las locuciones nominales. Otro grupo de voces argóticas del que hablan constantemente los estudiosos del argot son los préstamos, sin embargo, estos ya los hemos comentado en el anterior apartado. Por último, encontramos casos de parónimos y variantes formales, algunos con motivación humorística nacidos en el seno del habla popular.

\subsubsection{La formación de palabras}

Los procedimientos de la formación de palabras están escasamente representados en el "Vocabulario". No hemos localizado ningún ejemplo de derivación -aunque sospechamos que los haya, pero son casos en los que no hemos sido capaces de descifrar la base, como veremos más abajo- y solo dos ejemplos de composición. La composición sigue siendo un tema polémico entre sus estudiosos y no es nuestra intención entrar aquí y ahora en el debate. Por tanto, nos hemos limitado a seguir la clasificación que ofrece la NGLE (ASALE 2010) y clasificamos como compuestos tan solo los propios o univerbales, y los sintagmáticos; los compuestos sintácticos los clasificaremos como locuciones nominales.

Cagalumbre 'Pistola' (sin documentar); Sobrepuesta 'Chaqueta' (Aguilar 1941: sobre-puesta 'chaqueta'; Chabat 1964: sobrepuesta 'chaqueta'; cf. en Santamaría 1942 y en el $D A$ encontramos la voz sobrepuesto 'En Méjico y otras partes, parche, enmienda, superpuesto, que se echa a la parte descosida o rota' y 'Mx. Pedazo de tela, o piel, que se pega sobre una cosa, generalmente para tapar un agujero', respectivamente. Una alternativa a la composición sería que sobrepuesta se interpretara como una evolución metafórica de sobrepuesto con una adaptación analógica del género femenino inducida por chaqueta, pero mientras no tengamos más datos que avalen la hipótesis, clasificamos sobrepuesta como un compuesto).

\subsubsection{Transformaciones semánticas}

Como ha sido de esperar, las transformaciones semánticas son el grupo más numeroso de nuestro pequeño corpus. Son 47 en total y de ellas solo 3 se clasificarían como metonimias, mientras que metáforas serían 44 . En todos los casos se trata de términos motivados y evocadores y, como afirma Sanmartín (1998: 80-81), en su formación “obedecen a causas psicológicas, en especial a los factores emotivos y a la búsqueda de intensificación (expresividad para muchos)". No obstante, frecuentemente, la motivación 
no está del todo clara, "puesto que en muchos casos no sólo la metáfora se basa en otras metáforas anteriores, sino que crea la propia semejanza" (ibíd.).

En primer lugar dirigiremos la mirada hacia metonimias, productos de sustitución de nombre de una cosa por uno de sus atributos. Son solo 3, como ya hemos dicho: fierro 'centavo', por el material de fabricación; jarano 'hombre del pueblo' (por el sombrero que solían llevar); y parrales 'frijoles' (de Parral, municipio de Chihuahua, famoso por producción de un tipo de frijol).

Fierro 'Centavo' (Ramos i Duarte 1895: Fierro 'Peso (moneda). "Me debe usted un fierro," dicen los pelados, en vez de un peso'; Santamaría 2000 [1959]: 2. 'Genéricamente, dinero, entre el vulgo. Ú. pm. en pl.'; Chabat 1964: 'centavo'; Colín 1991: fierros (tener) 'dinero'; DA: Mx, vulg. Dinero, moneda corriente'; $D L E$ : '4. m. Méx. centavo (Imoneda)' y '7. m. pl. Méx. dinero (moneda corriente)') $)^{5}$; Jarano 'Ídem. [hombre] del pueblo (Ramos i Duarte 1895: 'Sombrero de paja, de ala ancha y copa alta. También llamamos jarano al sombrero de pelo, de copa alta, ala grande y galoneada. El jarano de los jarochos de Veracruz es el sombrero charro de Méjico, Puebla y Querétaro'; Santamaría 2000 [1959]: 'Sombrero de fieltro, de copa alta y ala ancha, generalmente galoneado y con cordón rematado en borlas. Por analogía, se llama así cualquier sombrero, aun el de paja, de forma semejante. En el interior más comúnmente charro'; $D A$ y $D L E$ : 'sombrero jarano'; cf. Aguilar 1941: 'La víctima'; Chabat 1964: 'La víctima, tonto; al que van a robar'; Colín 1991: 'Víctima del robo'); Parrales 'Frijoles' (Aguilar 1941: parrales 'frijoles'; Amor 2014 [1947]: frijoles 'parrales, parraleños; Chabat 1964: parrales 'frijoles' y parraleños 'frijoles'; Colín 1991: parrales 'frijoles'; cf. Ramos i Duarte 1895: parralanda 'comida'; y sobre todo Santamaría 1942: parraleño, $\tilde{n} a$ ' [...] hay un frijol especial, rayado de rojizo y amarillo, llamado frijol parraleño, muy estimado en comercio, en Méjico').

En lo que atañe a las metáforas, todas son, sin lugar a dudas, transposiciones basadas en similitud de aspectos, de usos o de funciones. Sanmartín (1998) en su estudio sobre el argot español documenta diversos tipos de metáforas con estructura interna, de acuerdo con los postulados de Lakoff y Johnson (1980), que también, naturalmente, se pueden identificar aquí.

El primer tipo serían las metáforas estructurales, es decir, cuando un concepto se organiza metafóricamente en términos de otro. El vehículo de

5 Cf. otra metonimia fierro 'arma blanca': Franco 2014 [194?]: 'Arma blanca o de fuego'; Aguilar 1941: 'cuchillo'; Chabat 1964: 'cuchillo; centavo; tranvía; órgano sexual masculino'. 
la metáfora puede ser otro objeto (alicates 'pies'; cáscara 'reloj'; campana 'saya'), puede ser un animal (gamuza 'pan de la cárcel'; mula 'amujerado'; perico 'muchacho preso'; toro 'carne') o un color (alazán 'oro'; blanca 'plata').

El segundo serían las ontológicas en las que consideramos acontecimientos, actividades, emociones, ideas, etc., como entidades y sustancias (lisa 'mascada'; lima 'camisa'; refinar 'comer'; patinar 'barrer por castigo'; o pecadora 'leontina').

Por último, quedarían las metáforas orientacionales y tiene razón Sanmartín cuando dice que "apenas poseen rentabilidad en el argot" (1998: 88 ), ya que faltan también en nuestro grupo.

Alicates 'Pies' (Ramos i Duarte 1895: 'Pies'; cf. DLE: 'tenaza pequeña de acero con brazos encorvados y puntas cuadrangulares o de forma de cono truncado, [...]'); Alazán 'Oro (moneda)' (Ramos i Duarte 1895: 'Oro'; Santamaría 2000 [1959]: 'En el caló carcelario, el oro'; Aguilar 1941: 'Reloj de oro, o moneda de oro'; Chabat 1964: 'Reloj de bolsillo, reloj de oro', cf. también alazanas 'monedas de oro' y aplazano 'reloj de bolsillo'; Colín 1991: 'Reloj de bolsillo'); Blanca 'Plata' (Chamorro 2002: 'moneda blanca, género de moneda de muy baja ley'; Ramos i Duarte 1895: 'Plata'; Chabat 1964: blanco y blanca 'plata'; DLE: desus. 'moneda de plata'); Caballos 'Calzones' (Ramos i Duarte 1895: 'Calzones'; Aguilar 1941: 'Calzones'; Chabat 1964: 'Calzones de mujer'); Campanas 'Enaguas' (Chamorro 2002: Campana 'Saya o basquiña'; Hernández Alonso y Sanz Alonso 2002: ídem.; Salillas 1/1896: campana 'saya'; Salillas 2/1896: campana (germ.) 'saya'; Ramos i Duarte 1895: 'Enaguas, es voz de la germanía [...]'; Amor 2014 [1947]: enaguas 'campana'; Aguilar 1941: campanas 'enaguas o faldas'; Chabat 1964: ídem.; Colín 1991: campanas 'falda'; DLE: campana Germ. 'Saya o basquiña'); Cantear 'Errar' (Ramos i Duarte 1895: 'Errar'; Santamaría 2000 [1959]: 'Ladear, inclinar, poner de canto una cosa'; $D A$ : Gu, Ni. Torcerse un asunto, ejecutar alguien algo mal, con torpeza; DLE: Nic. Echar a perder algo); Cáscara 'Reloj' (Ramos i Duarte 1895: 'Reloj de bolsillo'; Aguilar 1941: cáscara de muñeca 'reloj de pulsera'; Chabat 1964: cáscara 'reloj de bolsillo', cáscara amarilla 'reloj de oro', cáscara de muñeca 'reloj de pulsera'; Colín 1991: cáscara 'viejo, reloj de bolsillo, traje, bolsillo'); Charrasca 'Cuchillo ó arma de hojalata' (Ramos i Duarte 1895: 'Cuchillo ó arma de hojalata'; Santamaría 2000 [1959]: 'Cuchillo, arma blanca gastada, laminada y filosa, por lo común de hojalata. Es el arma propia del pelado'; Amor 2014 [1947]: cuchillo 'charrasca'; Franco 2014 [194?]: 'Arma arrastradiza hecha de materiales diversos; navaja de muelles'; Aguilar 1941: 'Fleje con punta o cuchillo'; Chabat 1964: 'Cuchillo, fleje con punta'; Colín 1991: ‘Arma blanca, cuchillo, navaja'; 
$D A$ : Mx. 'Arma blanca, especialmente un cuchillo, que está gastada y deteriorada'; $D L E$ : fest. coloq. 'Arma arrastradiza, por lo común el sable. |coloq. Navaja de muelles'); Clavo 1 'Fistol' (Ramos i Duarte 1895: 'Prendedor, fistol'; Chabat 1964: 'Fistol de corbata'); Clavo 2 'Prendedor' (Ramos i Duarte 1895: 'Prendedor, fistol'); Concha 'Bolsas' (Aguilar 1941: 'Bolsa del chaleco’; Chabat 1964: 'Bolsa de chaleco, holgazán’); Confite 'Bala' (sin documentar); Cuchillo 'Vaso' (Chabat 1964: 'Vaso cervecero'; Colín 1991: 'Vaso de cerveza'); Culebro 'Reboso' [sic] (Ramos i Duarte 1895: 'Rebozo: manta con que se abrigan las mujeres'; Santamaría 2000 [1959]: 'Vulgarismos del interior, por rebozo'; Chabat 1964: 'Rebozo'; Colín 1991: 'Rebozo, homosexual'); Diamante 'Décimo (moneda)' (Ramos i Duarte 1895: 'Moneda de cien centavos. Décima parte de un peso, por lo que el vulgo le llama décimo'); Escupidora 'Pistola' (Amor 2014 [1947]: pistola 'escupidera'; Aguilar 1941: 'pistola'; Chabat 1964: 'pistola'; Colín 1991: 'pistola'); Filero 'Cuchillo' (Ramos i Duarte 1895: 'El cuchillo’; Santamaría 2000 [1959]: 'Cuchillo, entre la gente del hampa'; Amor 2014 [1947]: cuchillo 'lero' [¿sic?]; Aguilar 1941: 'Cuchillo'; Chabat 1964: 'Cuchillo, puñal'; Colín 1991: 'El que ataca con navaja, puñal o "punta"'); Filosa 'Cara' (Amor 2014 [1947]: boca 'filosa' y cara (humana) 'fila'; Aguilar 1941: 'boca' y fila 'cara'; Chabat 1964: filosa 'navaja, cara, rostro' y filosa 'boca'; Colín 1991: 'Boca, cuchillo, navaja’; cf. Chamorro 2002 y Hernández Alonso y Sanz Alonso 2002: filosa 'espada'; DLE: Germ. Espada (arma blanca); confluencia de dos metáforas); Gamuza 'Ídem [pan] de la cárcel' (sin documentar); Grande 'Peso (moneda)' (Aguilar 1941: Un grande 'Un peso'; Chabat 1964: ídem.; Colín 1991: Grande (Un) 'Billete de mil pesos'); Ingenieros 'Albañiles' (sin documentar; DLE: desus. 'Persona que discurre con ingenio las trazas y modos de conseguir o ejecutar algo'; análogo a alarife 'maestro de obras', por extensión 'maestro en otras cosas', cf. Frago 2003); Libro 'Baraja' (Chamorro 2002: Libro de cuarenta y ocho 'Baraja de naipes'; Hernández Alonso y Sanz Alonso 2002: Libro de cuarenta y Libro real 'La baraja'; Chabat 1964: 'Baraja'; Colín 1991: 'Naipes, baraja'; DLE: libro de las cuarenta hojas coloq. 'Baraja de naipes'); Lima 'Camisa' (Chamorro 2002: 'La camisa'; Hernández Alonso y Sanz Alonso 2002: ídem.; Salillas 1/1896: 'Camisa'; Salillas 2/1896: germ. 'Camisa'; Amor 2014 [1947]: Camisa 'Lima'; Aguilar 1941: 'Camisa'; Chabat 1964: ídem.; Colín 1991: ídem.); Linternas 'Ojos' (Chamorro 2002: ‘El ojo'; Hernández Alonso y Sanz Alonso 2002: ídem.; Santamaría 2000 [1959]: 'En sentido metafórico, ojo, en lenguaje familiar'; Colín 1991: Linternas 'Ojos'); DA: I. 1. f. $\mathrm{Mx}, \mathrm{Cu}$; f. pl. Bo:E,N,O, Py. | metáf. farol, ojos. pop + cult $\rightarrow$ espon.); Lisa 'Mascada' (Aguilar 1941: 'Mascada de pecho'; Chabat 1964: 'Pañuelo de seda, camisa, billetera, cartera'; Colín 1991: 'Billetera, cartera'); Maceta 
'Cabeza' (Santamaría 2000 [1959]: 'En sentido figurado, la cabeza y, por extensión mata recia de pelo’; Aguilar 1941: 'Cabeza'; Chabat 1964: ídem.; Colín 1991: 'Cabeza humana, bacín o bacinica, ataúd'; $D A$ : f. Bo; $\mathrm{Gu}$, ES, Ni, Pa, pop; Mx. fest. 'Cabeza de una persona. pop + cult $\rightarrow$ espon.'; DLE: coloq. Guat., Méx. y Nic. 'Cabeza de una persona'); Maje 'Al robado' [probablemente 'persona robada' y no 'cosa robada'] (Santamaría 2000 [1959]: 'Nombre que se da vulgarmente al indio, en lugares del interior, como codocho, chondique y otros'; Amor 2014 [1947]: Hombre (Ingénuo que puede ser la presunta Víctima) 'Maje'; Franco 2014 [194?]: Maje 'Tonto (falto de entendimiento o de razón). Buscar al maje, para conseguir dinero'; Aguilar 1941: Maje y Majetriste 'Tonto'; Chabat 1964: 'Tonto, al que van a robar, hombre rústico'; Colín 1991: 'Tonto, malo'; DA: Mx, Gu, Ho, ES, Ni, CR. 'Referido a persona, tonta. pop + cult $\rightarrow$ espon.'; DLE: C. Rica, El Salv., Hond., Méx. y Nic. 'tonto (\| falto de entendimiento o de razón). No sea usted maje, no deje que lo boten del trabajo'); Mula 'Amujerado' (Aguilar 1941: 'Pederasta pasivo’; Chabat 1964: ídem.; Colín 1991: Mula (ser una) 'Perverso, malo, ingrato, no confiable, homosexual pasivo, hombre impotente'); Paloma 'Sábana' (Chamorro 2002: 'Sábana'; Hernández Alonso y Sanz Alonso 2002: ídem.; Salillas 1/1896: ídem.; Aguilar 1941: Palomas 'Sábanas'; Chabat 1964: Palomas 'Sábanas, vagabundos'; DLE: germ. 'Sábana de la cama'); Papeles 'Billetes de banco' (cf. Salillas 2/1896: Papil y Papiro 'Billete de banco'; DLE: papel 'Documento que contiene la obligación del pago de una cantidad, como una libranza, un billete de banco, un pagaré, etc. 1000 dólares en metálico y 100 en papel'); Papira 'Cartera' (Amor 2014 [1947]: Billetera 'Pápira'; Aguilar 1941: Pápira 'Billetera'; Chabat 1964: Pápira 'Billetera, Baraja; Colín 1991: 'Baraja, cartas para jugar, naipes'); Pasar 'Dar' (sin documentación); Pasma 'Policía secreta' (Salillas 2/1896: Pasma 'La policía'; Santamaría 2000 [1959]: 'Término jergal del interior, usado para llamar al gendarme o agente del orden, guardia civil'; Aguilar 1941: 'Policía reservada'; Chabat 1964: 'Policía uniformado', 'La víctima, tonto, hombre rústico'; Colín 1991: 'Policía preventivo'; DLE: jerg. 'Policía (cuerpo de seguridad)'); Patinar 'Castigo de barrer' [isic! 'Barrer por castigo'] (sin documentar); Pecadora 'Leontina' (sin documentar); Perico 'Muchacho preso' (sin documentar; cf. DLE: Nic. 'aprendiz (persona que aprende algún oficio)'); Pozo 'Bolsas' (Amor 2014 [1947]: Bolsa (del pantalón) 'Posa' [isic!]; Aguilar 1941: 'Bolso de mujer'; Chabat 1964: 'Bolso de mujer. Bolsa del traje’; Colín 1991: 'Bolsillo'); Refinar 'comer' (Amor 2014 [1947]: Comer (dulce después de fumar mariguana, costumbre del vicioso) 'Refinar'; Franco 2014 [194?]: 'Comer'; Aguilar 1941: 'Comer para contrarrestar los efectos de la mari-[huana]'; Chabat 1964: 'Comer. Comer dulces después de fumar marihuana'; Colín 1991: 'Comer, beber, realizar el 
acto social'; $D A: \mathrm{Mx}$; Pa, vulg. 'Comer. pop + cult $\rightarrow$ espon.'); Rienda 'Cadena del reloj' (Amor 2014 [1947]: Cadena (de reloj) 'Rienda'; Franco 2014 [194?]: 'Cadena; Pulsera; esclava de oro'; Aguilar 1941: 'Cadena de reloj, leontina'; Chabat 1991: 'Cadena de reloj. Órgano sexual masculino'); Suave ‘Bueno' (Santamaría 2000 [1959]: 'En sentido vulgar y hasta pornográfico, apetecible, admirable. Dícese prm. de la mujer.-2. Grande o descomunal. Le aplicaron una paliza SUAVE. Vulgarismo reprochable'; Chabat 1964: 'Bueno, bonito, satisfecho, sí'; Colín 1991: 'Bueno, agradable'); Tabique 'Cárcel' (Ramos i Duarte 1895: 'Ladrillo de bases cuadradas. Se llama tabique la pared delgada que sirve para separar dos piezas ó aposentos de una habitación'; Santamaría 2000 [1959]: 'Ladrillo que tiene caras cuadrangulares planas'; Amor 2014 [1947]: Cárcel 'Tabique'; Aguilar 1941: 'Cárcel, prisión, presidió, penitenciaría'; Chabat 1964: 'Cárcel, prisión, pan'; Colín 1991: 'Cárcel'; $D A$ : Mx. 'Ladrillo, masa rectangular de barro para construir muros. | [...] | ES, Ni. Cárcel'; DLE: Méx. 'ladrillo (| masa rectangular de arcilla)'); Toro 'Carne' (sin documentación); Trabucos 'Pantalones' (Amor 2014 [1947]: Pantalón 'Trabuco'; Aguilar 1941: Trabucos 'Pantalones'; Chabat 1964: Trabucos 'Calzones, pantalones'; Colín 1991: Trabuco 'Pantalón'y Trabucos y Trabucones 'Calzoncillos'); Trozo 'Cortaplumas' (sin documentación'); Vieja 'Presa' (Ramos i Duarte 1895: 'Concubina, manceba'; Santamaría 2000 [1959]: 'Por antonomasia o por donaire, la esposa o la mujer del soldado'; $D A$ : $\mathrm{Mx}, \mathrm{Ho}, \mathrm{CR}, \mathrm{Bo}$. 'Mujer de cualquier edad. desp.'; DLE: coloq. Bol. y Méx. 'mujer (\| persona del sexo femenino)').

\subsubsection{Variación formal. Parónimos}

Las voces o locuciones con variación formal constituyen un grupo muy reducido y a la vez bastante heterogéneo. Si la estructura se documenta con idéntica (o similar) forma y significado en algunos de los repertorios de consulta utilizados, podemos estar casi seguros de que se hallaba lexicalizada en el argot mexicano de la época (o por lo menos en el español popular de la zona). No obstante, en varias ocasiones no las hemos localizado en ningún repertorio de consulta y, por tanto, cabría admitir que se podría tratar de erratas $^{6}$.

Las locuciones cayetano 'cállate' y cayetano la botella 'cállate la boca' (junto con otras variantes) o el adverbio de afirmación simón 'sí' están documentados también en otras fuentes; sin embargo, para guiñar 'dar',

6 Hubo erratas como lemas incluso en el Diccionario académico, cf. Buzek 2010. 
pisarse 'fugarse', marisanza 'marihuana', tando 1 'dinero' y tostador 'tostón' no tenemos documentación adicional y, por tanto, hay que obrar con cautela. Guiñar se parece bastante a diñar 'dar', pisarse a pirarse 'fugarse' y tando 1 a jando 'dinero', y los tres son gitanismos bien documentados. Marisanza puede ser un ocasionalismo y tostador tan solo una variante formal de tostón 'moneda de plata', tal vez con fines humorísticos.

Cayetano 'Cállate' (Ramos i Duarte 1895: 'Cállate'); Cayetano la botella 'Cállate la boca' (Ramos i Duarte 1895: 'Cállate la boca'; Santamaría 2000 [1959]: 'Paronimia jocosa de "Cállese la boca”. Usualísima también en Centro América, donde se dice además cayetano la bocina'; Colín 1991: Cayetano la buchaca 'Imperativo: calla la boca'; DA: a. es buen amigo. Gu. p.u. 'cayetano es buen muchacho' y b. es buen muchacho. fr. prov. Ho, Ni. p.u. 'Indica que alguien debe callarse o ser discreto. pop + cult $\rightarrow$ espon'); Guiñar 'Dar' (sin documentación); Marisanza 'Ídem. [mariguana] corriente' (sin documentación); Pisarse 'Fugarse' (cf. Chabat 1964: pirarse 'irse, huir'; DA: intr. prnl. Pa, Co. 'Irse.' cult. [será un homónimo o evolución paralela]); Simón 'Sí (afirmando)' (Ramos i Duarte 1895: 'Sí, cierto'; Franco 2014 [194?] 'Sí'; Chabat 1964: 'Sí'; Colín 1991: 'Sí'; DA: Mx, Gu, Ho, ES, Ni, Ec, Bo. juv. 'Sí'); Tando 1 'Dinero' (sin documentación; cf. Rebolledo 2006 [1909] Jandorró 'Dinero'); Tostador 'Tostón (moneda)' (Ramos i Duarte 1895: Tostón 'Moneda de plata que representa el valor cincuenta centavos de un peso'; Santamaría 2000 [1959]: Tostón 'Moneda de plata, de a cuatro reales, en el antiguo sistema monetario; de cincuenta centavos, en el actual. Lo mismo en Colombia'; Amor 2014 [1947]: Tostón (cincuenta centavos) 'Michi').

\subsubsection{Unidades fraseológicas}

Las unidades fraseológicas recogidas en el "Vocabulario" son muy pocas y en general se trata de locuciones, puesto que el enunciado fraseológico ¿Qué ubres? ‘¿Qué hubo?', indocumentado en otras fuentes, parece más bien una creación humorística espontánea.

Las locuciones verbales son tres: poner una cama 'tender una trampa a alguien', dar la canción 'entretener', y pelarse el jalisco 'mirar'; cinco son nominales: chica grande 'un real de pulque', rienda suelta 'leopoldina', tando suave 'sombrero ancho', tlaco grande 'medio de pulque' y una de arroz '[medida de] dos centavos de pulque'; y una es adverbial: nel de velada 'no'.

¿Qué ubres? ‘QQué hubo?' (sin documentación); Poner una cama ‘Formar un plan ó complot para atacar á alguien' (Chamorro 2002: 'Tender trampa a un ladrón, preparar a la víctima de un robo'; Santamaría 2000 [1959]: tenderle uno la cama a otro. fig. fam. [...]-2. 'Ponerle una celada, 
prepararle un artificio para hacerle mal'; DLE: hacerle a alguien la cama. 'Trabajar en secreto para perjudicarlo'); Dar la canción 'Entretener' (Ramos i Duarte 1895: 'Entretener'); Pelarse el jalisco 'Mirar, poner atención' (Ramos i Duarte 1895: Pelar el jalisco 'Ver, fijar la vista'; Colín 1991: Jalisco (pelar) 'Ver, observar'; cf. DA: Pelarse. Mx, Ho, Ni. 'Prestar atención a alguien o a algo. pop'); Nel de velada 'Nó (negación)' (Franco 2014 [194?] Nel 'No'; Chabat 1964: Nel 'Sí'; Colín 1991: Nel 'Sí, por supuesto, úsase también como negación'; $D A$ : Mx; Gu, Ho, ES, $\mathrm{Ni}, \mathrm{CR}$, juv; Pe, p.u; urb. 'No, nada, de ninguna manera. pop'); Chica grande 'Un real ídem [de pulque]' (Ramos i Duarte 1895: 'Un real de pulque, doce centavos'); Rienda suelta 'Leopoldina' (sin documentación); Tando suave 'Ídem [sombrero] ancho' (sin documentación); Tlaco grande 'Medio ídem [de pulque]' (sin documentación); Una de arroz 'Dos cts. [centavos] de pulque' (sin documentación).

\subsubsection{Voces de procedencia oscura}

Al final aportamos un listado de voces sobre cuyo proceso de formación no sabemos casi nada. Por su estructura intuimos que la mayoría serán derivados o compuestos patrimoniales (barandal 'baratillo'; doráis 'gendarme'; ferrolana 'comida de la calle'; pantofacia 'comida de la cárcel') aunque tampoco podemos descartar posibles indigenismos léxicos (tanico 'paquete de dinero' o tuje 'zarape'). Varias de ellas no están documentadas en otras fuentes (orle 'enaguas blancas'; o tonedo 'atole'), mientras que otras están bien avaladas (chutia 'vidrio usado como arma'; furris 'malo'; mota 'marihuana'; o soria 'tortilla').

Barandal 'Baratillo' (Ramos i Duarte 1895: 'Baratillo'); Besuco 'Viejo' (sin documentación); Chutia 'Vidrio (como arma)' (Ramos i Duarte 1895: 'Pedazo de vidrio que los presidiarios usan como arma para la riña'; Santamaría 1942: 'En caló mejicano, navaja. V. chute. (Como chutria, entre gitanos). -2 . Por extensión, pedazo de vidrio cortante o puntiagudo, usado a guisa de arma en riña. (También en gitano jutia es aguja y se usa en el caló español.)'; Santamaría 2000 [1959]: 'En caló carcelario mejicano, navaja. V. chute.'; Aguilar 1941: 'Cuchillo, navaja'; Chabat 1964: 'Cuchillo, navaja'; Colín 1991: 'Navaja, cuchillo, puñal'); Doráis 'Gendarmes' (Aguilar 1941: 'Gendarme'; Chabat 1964: 'Gendarme, jefe'); Esquelo 'Al robado' [probablemente 'persona robada' y no 'cosa robada'] (Chabat 1964: 'Robado'); Ferrolana 'Comida de la calle' (Ramos i Duarte 1895: 'Comida'); Furris 'Malo' (Ramos i Duarte 1895: 'Muy malo, despreciable. Furris, en Aragón, significa tramposo, embrollón'; Santamaría 2000 [1959]: 'Malo, mal hecho, despreciable'; Aguilar 1941: fúrris 'falso'; Chabat 1964: 'Falso, feo, de poco valor, 
ridículo'; Colín 1991: 'Feo, corriente, de ínfima calidad, tonto, persona ridícula, mal vestido'; $D A$ : $\mathrm{Mx}$; Ho, ES, Ni, juv. 'Referido a cosa, de poca calidad, de poco valor. pop. 2. Mx. Malo, despreciable, mal hecho. pop.'; $D L E$ : coloq. Ál., Ar., Méx. y Nic. 'Malo, despreciable, mal hecho|2. adj. coloq. C. Rica y Méx. Feo, horrible'); Güicho 'Pañuelo' (Santamaría 2000 [1959]: 'En lenguaje de germanía, nombre que se da al pañuelo'; Amor 2014 [1947]: Pañuelo 'Huilo'; Aguilar 1941: Güicho ‘Pañuelo’ y Güilo o Huilo 'Pañuelo'; Chabat 1964: Güicho 'Pañuelo’ y Güilo 'Pañuelo'; Colín 1991: Güicho 'Pañuelo'); Jano 'Hombre decente' (Aguilar 1941: Jaño 'Hombre'; Chabat 1964: Jaño 'Hombre'); Jaña 'Mujer decente' (Amor 2014 [1947]: Mujer 'Jaña'; Aguilar 1941: 'Mujer, amasia'; Chabat 1964: 'Mujer, amasia, vieja'; Colín 1991: 'Mujer, muchacha, novia'); Jaspia 'Hambre' (Amor 2014 [1947]: Hambre 'Jáspia'; Franco 2014 [194?]: 'Hambre'; Aguilar 1941: 'Hambre'; Chabat 1964: 'Hambre'; Colín 1991: 'Hambre, apetito'; DA: Mx, Gu, Ho. 'Hambre. carc.'); Majo 'Ídem [hombre] engañado' (sin documentación); Mota 'Mariguana fina' (Santamaría 2000 [1959]: 'Nombre que se da también, entre la gente del pueblo, a la marihuana o juanita'; Amor 2014 [1947]: Mariguana 'Mota'; Franco 2014 [194?]: 'Mariguana'; Chabat 1964: 'Marihuana'; Colín 1991: 'Marihuana'; $D A$ : Mx, Gu, Ho, ES, Ni, CR, PR, Co:N, Ve, Ec. 'Marihuana. drog.'; DLE: C. Rica, El Salv., Guat. y Méx. 'Marihuana'); Orle 'Enaguas blancas' (sin documentación); Pantofacia 'Comida de la cárcel' (sin documentación); Pitoche 'Medio (moneda)' (Aguilar 1941: 'Medio'; Colín 1991: Pitoche (medio) 'Un poco'; tal vez por metáfora- 'de escaso valor'; cf. DA: ni pitoche. $\mathrm{Cu}$. 'Absolutamente nada. pop.'; DLE: un pito coloq. 'Muy poco o nada'); Riñero 'Ratero' (sin documentación; cf. Amor 2014 [1947], Aguilar 1941 y Chabat 1964: Riño y Riñón 'Ladrón'); Soria ‘Tortilla' (Amor 2014 [1947]: Tortilla 'Sorias'; Aguilar 1941: Sorias 'Tortillas'; Chabat 1964: Sorias 'Tortillas'; Colín 1991: Sorias 'Tortillas'); Sura 'Peseta (moneda)' (Amor 2014 [1947]: Peseta (Veinticinco centavos) 'Sura'; Aguilar 1941: 'Peseta', cf. Surata 'Peseta'; Chabat 1964: 'Veinte y cinco centavos, peseta', cf. Sura de varos 'Veinte y cinco pesos' y Surata 'Veinte y cinco centavos, peseta'; Colín 1991: 'Moneda de veinticinco centavos'); Tando 2 'Sombrero decente' (Amor 2014 [1947]: Sombrero 'Tando'; Aguilar 1941: 'Sombrero'; Chabat 1964: 'Sombrero'; Colín 1991: 'Sombrero'); Tanico 'Paquete de dinero' (sin documentación); Tonedo 'Atole’ (sin documentación); Tuje 'Sarape [sic] (Aguilar 1941: Tule 'Zarape'; Chabat 1964: Tuje 'Sarape, cobija' y Tule 'Sarape, cobija'; Colín 1991: 'Manta, cobija, sarape'). 


\subsection{VOCES INDOCUMENTADAS: ¿PROPIAS DEL ARGOT CARCELARIO DE LA ÉPOCA?}

Hay un grupo bastante numeroso de unidades léxicas del "Vocabulario", son 45 en total, para las que no hemos encontrado ninguna documentación mexicana complementaria, o "de control"; es decir, no estamos seguros de si realmente pertenecían al argot carcelario mexicano de la época o no, puesto que siempre tenemos en la memoria la afirmación de Lara (1992) de que las voces jergales casi siempre han sido recolectadas por personas ajenas a los grupos marginados, por lo que sus competencias lingüísticas habrá que tomarlas con cierta reserva.

Diez de ellas se recogen en el Diccionario de mejicanismos de Ramos i Duarte (1895), sin embargo, esto no quiere decir que podamos considerarlas avaladas. Hay una indiscutible filiación entre el "Vocabulario" y el diccionario de Ramos i Duarte (cf. Buzek y Gazdíková 2017) pero Ramos i Duarte escogió tan solo una veintena de voces del comienzo del alfabeto y no sabemos con qué criterios. Puede que después de haber pasado varias décadas en México -Ramos i Duarte era cubano- las haya escogido guiándose por su propia competencia u otros factores subjetivos; otra posibilidad sería que el "Vocabulario" de la novela y el diccionario de Ramos i Duarte tuvieran una fuente común, todavía desconocida. Ante las dudas nos parece más prudente tomar el testimonio de Ramos i Duarte con reserva. Son las siguientes voces: alicates 'pies', barandal 'baratillo', bruje 'real (moneda)', dar la canción 'entretener'; cantear 'errar', cayetano 'cállate', chica grande 'un real de pulque, doce centavos', clavo 'prendedor, fistol', y ferrolana 'comida'.

Otras seis palabras se encuentran en el interior de la novela en un contexto más amplio que ilustra el uso: pantofacia 'comida de cárcel', papel 'billete', patinar 'barrer por castigo', tonedo 'atole', toro 'carne', tostador 'tostón (moneda) ${ }^{7}$. Somos conscientes de que resulta metodológicamente arriesgado avalar el léxico del "Vocabulario" por el uso que se hace de las palabras dentro del contexto de la novela misma, pero creemos que se puede justificar por la desproporción tan llamativa entre las palabras de la lista y el poco uso que se hace de ellas en el interior de la novela. De las 115 unidades léxicas argóticas recogidas en el "Vocabulario" solo 18 aparecen en el texto de la obra. Parece como si el "Vocabulario" procediera de otra fuente y García

\footnotetext{
7 Como ya hemos advertido más arriba, al léxico carcelario presente en el interior de la novela le dedicaremos un estudio aparte.
} 
González así tan solo aprovechara los materiales que había recopilado para escribir la novela y que no se quedaran fuera.

Las 28 unidades léxicas que quedan son bastante heterogéneas. Cagalumbre 'pistola', catirro 'golpe', confite 'bala', esquelo 'robado', majo 'persona engañada', marisanza 'marihuana', pecadora 'leontina', tando 1 'dinero', tanico 'paquete de dinero', perico 'muchacho preso' y vieja 'presa' podrían pertenecer desde el punto de vista temático al argot delincuente y carcelario.

No obstante, unidades léxicas como una de arroz 'dos centavos de pulque', palo 'tina de pulque', tlaco grande 'medio de pulque', armar 'molestar', besuco 'viejo', clacoquis 'comprador', guiñar 'dar', ingeniero 'albañil', orle 'enaguas', pasar 'dar', pinto 'jarro', pisarse 'irse', rienda suelta 'leopoldina', tando suave 'sombrero ancho', tira 'cuartilla' y trozo 'cortaplumas' podrían pertenecer también al español mexicano popular de la época; el enunciado fraseológico ¿qué ubres? ‘¿qué hubo?’ es más bien una creación humorística (ocasional) del habla popular.

\subsection{Clasificación temática}

El argot carcelario es un sociolecto, así que no sorprende que se limite en buena medida a recoger voces que reflejen la realidad de la vida penitenciaria: la organización de la prisión, la jerarquía entre los presos, el ritmo diario de la vida carcelaria, ocupaciones y actividades, etc.

- Vida carcelaria: patinar 'barrer por castigo'; pisarse 'fugarse'; tabique 'cárcel';

- Personas en general y personas en la cárcel: chagorra 'mujer'; chamaco 'muchacho'; jano 'hombre decente'; jaña 'mujer decente'; jarano 'hombre del pueblo'; maje y majo 'persona robada o engañada'; mula 'amujerado'; nagual 'ladrón de la cárcel'; perico 'muchacho preso'; riñero 'ratero'; vieja 'presa';

- Comunicación: simón 'sí'; nel de velada 'no'.

Al mismo tiempo el argot carcelario también está relacionado con el argot de la delincuencia en un sentido más amplio y con el argot urbano común. Por lo tanto, comprende a su vez léxico de actividades delictivas, tipos de robos, especialidades de delincuentes, el léxico de juegos de azar, nombres de víctimas, dinero, drogas, etc. 
- Armas: cagalumbre o escupidora 'pistola'; charrasca 'cuchillo de hojalata'; chutia 'trozo de vidrio usado como arma'; confite 'bala', cuchillo 'vaso'; filero 'cuchillo';

- Objetos robados y actividades delictivas: cáscara 'reloj'; libro 'baraja'; pecadora 'leontina'; rienda 'cadena del reloj'; timar 'robar con engaño'; trincar 'robar';

- Policía: doráis o tecolote 'gendarme'; pasma 'policía secreta';

- Dinero: alazán 'oro'; blanca 'plata'; bruje 'real'; diamante 'décimo'; fierro 'centavo'; grande 'peso'; sura o mastica 'peseta'; papel 'billete'; papira 'cartera'; pitoche 'medio'; tando 'dinero'; tanico 'paquete de dinero'; tostador 'tostón';

- Fumar tabaco y marihuana: frajo 'cigarro'; juanita o mota 'marihuana fina'; marisanza 'marihuana corriente'.

Por otra parte, incluye también términos referentes al cuerpo humano o actividades vitales (beber, comer, dormir) y a la vestimenta.

- Cuerpo humano y sus funciones vitales: agüitar 'dormir'; alicates 'pies'; baiza 'mano'; filosa 'cara'; linternas 'ojos'; maceta 'cabeza'; jaspia 'hambre';

- Comer y beber: refinar 'comer'; una de arroz 'medida de pulque'; chica 'cuartilla de pulque'; chica grande 'un real de pulque'; brisa y toro 'carne'; ferrolana 'comida de la calle'; gamuza 'pan de la cárcel'; marro 'pan de la calle'; palo 'tina de pulque'; pantofacia 'comida de la cárcel'; parrales 'frijoles'; soria 'tortilla'; tira 'cuartilla'; tlaco grande 'medio de pulque'; tonedo 'atole';

- Vestimenta: caballos 'calzones'; campanas u orle 'enaguas'; chamarra 'blusa'; cincho 'ceñidor'; clavo 'prendedor'; concha o pozo 'bolsillo o bolsa'; culebro 'rebozo'; güicho 'pañuelo'; lima 'camisa'; lisa 'mascada'; rienda suelta 'leopoldina'; sobrepuesta 'chaqueta'; tando y tando suave 'sombrero'; trabuco 'pantalón'; tuje 'zarape';

Y al final, el argot suele sobrelexificar las mismas áreas y frecuentemente encontramos varios términos para un mismo referente (Sanmartín 1998 y 2006): cagalumbre o escupidora 'pistola'; doráis o tecolote 'gendarme'; juanita o mota 'marihuana fina'; sura o mastica 'peseta'; o brisa y toro 'carne'. 


\section{CONCLUSIONES}

Durante el estudio hemos visto que aunque es cierto que el argot mexicano guarda relaciones de parentesco lejano con el argot español (tanto de la época colonial, como de la de sus tiempos), posee a la vez varios rasgos que nos permiten identificarlo como propiamente mexicano o "nacional". Por una parte, se trata de frutos del contacto con las lenguas indígenas, pero es preciso volver a advertir que el léxico indígena es bastante escaso en el argot; como hemos señalado en otro sitio (Buzek 2017), el argot de la delincuencia siempre ha sido urbano y solían prevalecer en él tendencias de evolución patrimoniales. Estas evoluciones patrimoniales se notan no solamente en la lexicogénesis, sino también en los cambios de significado que obedecen las mismas tendencias como en otros argots hispánicos y en los argots en general. Vemos allí tendencias de animalización, degradación y humor, impregnadas a su vez de la cultura y las tradiciones populares mexicanas.

\section{REFERENCIAS BIBLIOGRÁFICAS}

Aguilar, José Raúl. 1941. Los métodos criminales en México. México: Ediciones Lux.

Alonso HernÁndez, José LuIs. 1979. El lenguaje de los maleantes españoles de los siglos XVI y XVII: la germanía (Introducción al léxico del marginalismo). Salamanca: Universidad de Salamanca.

Alvar Ezquerra, Manuel. 2004. Evocación y sucesos del Tesoro léxico de las hablas andaluzas. En Ignacio Ahumada (ed.). Lexicografia regional del español. VI Seminario de Lexicografía Hispánica, Jaén, 19 al 21 de noviembre de 2003, pp. 37-55. Jaén: Universidad de Jaén.

Amor, Ricardo. 2014 [1947]. Diccionario del hampa. Monterrey: Universidad Autónoma de Nuevo León.

Asociación de Academias de la Lengua Española. 2010. Diccionario de Americanismos. Madrid: Santillana.

Bustos Tovar, José Jesús. 1995. De la oralidad a la escritura. En Luis Cortés Rodríguez (ed.). El español coloquial. Actas del I Simposio sobre análisis del discurso oral. Almería, 23-25 de noviembre de 1994, pp. 9-28. Almería: Universidad de Almería.

1998. Lengua viva y lenguaje teatral en el siglo XVI: de los pasos de Lope de Rueda a los entremeses de Cervantes. En Wulf Oesterreicher, Eva Stoll y Andreas Wesch (eds.). Competencia escrita, tradiciones discursivas y variedades lingüisticas. Aspectos del español europeo y americano en los siglos XVI y XVII. Coloquio internacional, Friburgo en Brisgovia, 26-28 de Septiembre de 1996, pp. 421-444. Tübingen: Narr.

Buzek, Ivo. 2010. En torno a un fantasma académico: chislama 'muchacha'. En Daniel Vázquez e Ivo Buzek (eds.). Encuentro de Hispanistas (Brno, 9.-10. ř́jna 2009), pp. 231-241. Brno: Masarykova univerzita. 
2017. El léxico de las clases bajas en El Periquillo Sarniento. En Elena Carpi y Rosa M. García Jiménez (eds.). Herencia e innovación en el español del siglo XIX, pp. 45-74. Pisa: Pisa University Press.

Buzer, Ivo y Katarína Gazdíková. 2017. El léxico carcelario en el Diccionario de mejicanismos de Féliz Ramos i Duarte. Hesperia. Anuario de Filología Hispánica XX (1): 99-109.

Chabat, Carlos G. 1964. Diccionario de caló: el lenguaje del hampa en México. México: F. Méndez Oteo, Librería de Medicina.

Chamorro, María InÉs. 2002. Tesoro de villanos: lengua de jacarandina: rufos, mandiles, galloferos, viltrotonas, zurrapas, carcaveras, murcios, floraineros y otras gentes de la carda. Barcelona: Herder.

Colín SÁnchez, Gulllermo. 1991. Asi habla la delincuencia. México: Porrúa.

Company Company, Concepción. 2012. El español del siglo XVIII. Un parteaguas lingüístico entre España y México. En M Teresa García-Godoy (ed.). El español del siglo XVIII. Cambios diacrónicos en el primer español moderno, pp. 255-291. Bern: Peter Lang.

Frago Gracia, Juan Antonio. 2003. Alarife, un americanismo léxico entre la tradición y la innovación. Revista de Filología Española LXXXIII (3-4): 291-298.

Franco, J. L. 2014 [194?]. El Canerousse. Monterrey: Universidad Autónoma de Nuevo León.

García Frazier, Elena. 2006. Préstamos del náhuatl al español mexicano. Hesperia. Anuario de Filología Hispánica IX: 75-86.

García González, Francisco. 1894. La Chaquira (Belén por dentro). México: Imprenta "Reina Regente".

García Godoy, María Teresa. 1998. Las Cortes de Cádiz y América. El primer vocabulario liberal español y mejicano (1810-1814). Sevilla: Servicio de Publicaciones de la Diputación.

García ICazbalceta, Joaquín. 1899. Vocabulario de mexicanismos comprobado con ejemplos y comparado con los de otros países hispano-americanos. México: Tip. y Lit. "La Europea".

GARZA, JAMES AlEx. 2007. The imagined underworld: sex, crime, and vice in porfirian Mexico City. Lincoln-London: University of Nebraska Press.

Hernández Alonso, César y Beatriz Sanz Alonso. 2002. Diccionario de germanía. Madrid: Gredos.

Lara, Luis Fernando. 1992. El caló revisitado. En Elizabeth Luna Traill (ed.). Scripta Philologica in Honorem Juan M. Lope Blanch a los 40 años de docencia en la UNAMy a los 65 años de vida. Lingüística española e iberoamericana, tomo 2, pp. 567-592. México: Universidad Nacional Autónoma de México, Instituto de Investigaciones Filológicas.

Lope Blanch, Juan M. 1965. Influencia de las lenguas indígenas en el léxico del español hablado en México. Anuario de Letras 5: 395-402.

1969. El léxico indígena en el español de México. México: Colegio de México.

Martín Butragueño, Pedro. 2014. La división dialectal del español mexicano. En Rebeca Barriga Villanueva y Pedro Martín Butragueño (dirs.), Historia sociolingüística de México, tomo 3, pp. 1355-1409. México: El Colegio de México, Centro de Estudios Lingüísticos y Literarios.

Martínez, Olalla, Neus Vila Rubio, Luz Stella Castañeda y José Ignacio Henao. 2012. Formación e incorporación léxica en el argot español y en el parlache. En Neus Vila Rubio y Luz Stella Castañeda Naranjo (eds.). El argot entre España y Colombia. Estudios léxicos y gramáticos, pp. 15-55. Lleida: Edicions de la Universitat de Lleida.

OesterReicher, Wulf. 2004. Textos entre inmediatez y distancia comunicativas. El problema de lo hablado escrito en el Siglo de Oro. En Rafael Cano Aguilar (ed.). Historia de la lengua española, pp. 729-770. Barcelona: Ariel.

Ramos i Duarte, Féliz.1895. Diccionario de mejicanismos. Colección de locuciones i frases viciosas, con sus correspondientes críticas i correcciones fundadas en autoridades de la 
lengua; máximas, refranes, provincialismos y retoques populares de todos los Estados de la República Mejicana. Méjico: Imprenta de Eduardo Dublan.

Real Academia Española. 2014. Diccionario de la Lengua Española. 23 ${ }^{\mathrm{a}}$ ed. Madrid: Espasa.

Nuevo Tesoro Lexicográfico de la Lengua Española. Disponible en http://ntlle.rae. es/ntlle/SrvltGUISalirNtlle [Consulta 8/12/2017].

Real Academia Española y Asociación de Academias de la Lengua Española. 2010. Nueva gramática de la lengua española. Manual. Madrid: Espasa Libros.

Rebolledo, Tineo. 2006. Gitanos y castellanos. Diccionario gitano-español y español-gitano. Modelos de conjugación de verbos auxiliares y regulares en caló. Cuentos gitanos y castellanos. Historia de los gitanos desde su origen hasta nuestros días. $3^{\mathrm{a}}$ ed. Cádiz: Universidad de Cádiz. [Edición facsimilar basada en la de Barcelona-Buenos Aires, Maucci, 1909]

SAlillas, Rafael. 1896. El delincuente español. El lenguaje. Madrid: Librería de Victoriano Suárez.

Sanmartín SÁez, Julia. 1998. Lenguaje y cultura marginal: el argot de la delincuencia. València: Universitat de València.

2006. Diccionario de argot. Madrid: Espasa.

Santamaría, Francisco J. 1942. Diccionario general de americanismos. 3 tomos. Méjico: Editorial Pedro Robredo. 2000 [1959]. Diccionario de mejicanismos. Méjico: Porrúa.

Trejo, ARnulfo. 1961. El argot como medio de expresión en la prosa mexicana. Anuario de Letras 1: 173-179.

1968. Diccionario etimológico latinoamericano del léxico de la delincuencia. México: Unión Tipográfica Editorial Hispano Americana.

Universidad Nacional Autónoma de México y Biblioteca Nacional de México. Hemeroteca Nacional Digital de México. Disponible en http://www.hndm.unam.mx/index.php/es/ [28/1/2018]. 